\title{
MÍSTICA FEMININA MEDIEVAL: UM ENSAIO DE \\ CATEGORIZAÇÃO
}

\author{
Medieval female mysticism: a categorization essay
}

Maria Simone Marinho Nogueira ${ }^{1}$

\begin{abstract}
RESUMO
Neste artigo pretendemos mostrar um pouco do que nomeamos por mística feminina medieval. Além do que, queremos pensar um pouco sobre o tema para apresentá-lo como um conjunto de ideias que, apesar de não se realizar como um todo unívoco ou como uma única escola de pensamento, pode ser categorizado no seu conjunto por suas semelhanças que podem ser problematizadas. Desta forma, chamamos a atenção para dizer que qualquer investigação que seja feita sobre a mística feminina medieval, como indicam muitas estudiosas, deve levar em conta a necessidade de prestarmos atenção à perspectiva de gênero dos documentos existentes, afinal, é a partir deles que as mulheres místicas medievais falam. Assim, o artigo está divido em três partes: 1. uma abordagem da relação entre mística e filosofia; 2. uma apresentação da mística na Idade Média; e 3. a mística feminina medieval. Para realização do artigo, nos utilizamos de autores e autoras que estudam a mística, sobretudo a medieval, como Certeau (2015), Ruh (2002), McGinn (2017), Bingemer (2010), Cirlot e Gari (1999) e Troch (2013).
\end{abstract}

Palavras-chave: Mística feminina. Idade Média. Filosofia. Categorização.

\begin{abstract}
In this article we intend to show a bit of what we call medieval female mys ticism. Moreover, we want to think about it a bit to present it as a set of ideas that, although not realized as a single whole or as a single school of thought, can be categorized as a whole by their similarities that must be questioned. In this way, we call attention to say that an investigation about the medieval female mysticism, as many scholars indicate, must take into account the need for pay attention to the gender perspective of the existing documents, at last, it is from them that the medieval mystics women speak. Thus, the article is divided into three parts: 1. an approach to the relationship between mysticism and philosophy; 2. a presentation of mysticism in the Middle Ages; and 3. medieval female mysticism. For this paper, we use

\footnotetext{
${ }^{1}$ Professora do Programa de Pós-Graduação em Literatura e Interculturalidade (PPGLI) e da Graduação em Filosofia, da Universidade Estadual da Paraíba (UEPB). Doutora em Filosofia pela Universidade de Coimbra.

E-mail: mar.simonem@gmail.com ORCID: 0000-0003-1141-3911
} 
authors who study mysticism, especially the medieval, as Certeau (2015), Ruh (2002), McGinn (2017), Bingemer (2010), Cirlot and Gari (1999) and Troch (2013).

Keywords: Female mysticism. Middle Age. Philosophy. Categorization.

\section{Introdução}

Este artigo é fruto de três motivações. Duas de ordem mais pessoal, posto que desde a graduação em filosofia estudo a mística medieval e agora entendo que este assunto, mesmo ainda longe de se realizar como um todo, apresenta-se de forma mais madura não apenas pelo acréscimo de mulheres místicas aos homens místicos até então estudados na graduação, como também pela leitura da teoria da mística que ampliou a minha leitura sobre o tema. A segunda motivação diz respeito a percepção que tive de que os textos místicos produzidos por muitas mulheres são bastante diferentes dos produzidos pelos homens. Por fim, a terceira motivação vem de uma observação que foi feita na avaliação de um dos artigos em que fiz referência à mística feminina medieval e que apareceu da seguinte forma: "O que é a 'mística feminina medieval'? Uma categoria teológica, histórica? Cabe registrar e fornecer fontes, se é disso que se trata, e não de opinião de quem escreve o texto". Pois bem, tratemos então de registrar e fornecer fontes sobre o que chamamos de mística feminina medieval e vejamos se essa designação pode ser esquadrinhada na busca por uma possível sistematização ou categorização, isto é, se pode ser compreendida como um conjunto de ideias, conceitos, características, linguagens, que permitam identificar e reconhecer uma determinada linha de pensamento. Para tanto, o artigo será dividido em três partes. Na primeira abordaremos a mística em geral na sua relação com a filosofia. $\mathrm{Na}$ segunda parte focaremos mais especificamente na mística desenvolvida na Idade Média e, na terceira e última parte, abordaremos a mística feminina medieval.

\section{Mística e Filosofia}


A mística, por si só, já passa por algumas dificuldades para ser aceita nas academias devido a sua atopia, ou seja, o seu não-lugar. Esta dificuldade, por sua vez, diz respeito a uma série de questões dentre as quais destacaremos duas: sua relação muito estreita com a religiosidade e o estilo da sua escrita. Mas antes de adentrarmos nesses dois temas, tentemos traçar uma definição de mística e, para que não pareça apenas a opinião de quem escreve o texto, busquemos essa definição em alguns estudos.

O primeiro problema para quem estuda e, portanto, escreve sobre a mística, começa ao se tentar aproximar do termo com algum rigor $^{2}$. Isso porque ele sofreu ao longo da história muitos desgastes, tornando-se polissêmico e até ambíguo, como observa Velasco (1999) em seu livro El fenómeno místico, cujo primeiro capítulo se ocupa em dar conta, de forma rigorosa, do que seja a mística, apresentando as dificuldades daqueles que enveredam por tal estudo³ . Lima Vaz, por sua vez, seguindo na mesma direção de Velasco, afirma que uma das características da nossa cultura (ou da incultura da nossa época, nas suas palavras) é a deterioração ou o esvaziamento semântico de termos que nos deveriam ser caros como, por exemplo, a palavra éti$c a$. Prossegue dizendo que ocorre o mesmo com o termo mística, a quem coube a mesma infeliz sorte, pois: "Decaído de sua nobre significação original, acabou por designar uma espécie de fanatismo, com forte conteúdo passional e larga dose de irracionalidade.” (LIMA VAZ, 2000, p. 9).

Procurando escapar deste desgaste, e mesmo sabendo que não daremos conta de uma teoria da mística ${ }^{4}$ neste artigo, pensemos a mística aqui a

\footnotetext{
${ }^{2}$ Por falar em rigor, esclarecemos que "Apesar de alguns estudiosos/estudiosas usarem o termo mística e misticismo como equivalentes, gostaríamos de aqui fazer um breve esclarecimento. Normalmente o termo misticismo é uma tradução do inglês mysticism que, nesta língua, não soa pejorativo, não ocorrendo o mesmo quando se utiliza termo igual (misticis mo) nas línguas latinas. Daí preferirmos utilizar o termo mística, que vem do francês mystique, substantivo cuja origem, segundo Certeau (2015, p.24-25) data do século XVII. Logo, sempre que se encontrar a palavra misticismo neste artigo, trata-se do uso feito por alguns estudiosos que estão sendo citados." (VASCONCELOS e NOGUEIRA, 2020, p. 41).

3 Apenas para se ter uma ideia da discussão posta por Velasco, o primeiro capítulo do seu livro tem como título Cuestiones Preliminares e está dividido da seguinte forma: 1. «Mística». Uso y abuso de un término impreciso. 2. Fenómeno religioso y fenómeno místico. 3. A la búsqueda de un método para el estudio del fenómeno místico e 4. La mística como fenómeno humano. (VELASCO, 1999, 17-80).

4 Em termos mais gerais uma teoria da mística pode ser dividida em três grandes correntes, se assim podemos expressar: a Perenialista, também denominada de Filosofia Perene que tem, dentre os seus representantes, Aldous Huxley e Frithjof Schuon; a Contextualista, cujo nome em destaque é o de Steven Katz; e a corrente Deconstrutivista ou Pós-construtivista, também conhecida por Psicologia Perene e cujo principal nome é o de Robert Forman. A
} 
partir da origem desta palavra e como podemos defini-la. Deste modo, no que concerne à etimologia, a palavra mística deriva do grego mystikós (referente aos mistérios) que tem sua raiz, por sua vez, no verbo $m y o^{5}$, cujo significado é a ação de fechar, principalmente relacionada à boca e aos olhos. Podemos dizer, assim, que o sentido do termo mística faz referência a algo absconditus, secreto, que exige uma atitude de entrega ou de espera, uma vez que só pode ser percebido com os olhos do espírito, sendo o silêncio sua melhor expressão, daí o ato de fechar a boca e os olhos. Importa notar, em meio às várias definições que podemos encontrar de mística, que se trata de uma experiência do divino que produz uma transformação radical do ser humano e que esta experiência pode ocorrer com ou sem fenômenos, sejam extraordinários ou corporais ${ }^{6}$.

Para o estudioso da mística, no entanto, mesmo não desconsiderando determinados fenômenos e mesmo sabendo tratar-se de experiências pessoais e intransferíveis, o que nos resta para nos aproximarmos dela são os textos produzidos por aquelas e aqueles que tiveram uma experiência do absoluto ou, como escreve Certeau:

Já a partir do século XIII, isto é, desde que a teologia se profissionalizou, os espirituais e os místicos levantam o desafio da palavra. Eles são por isso deportados para o lado da "fábula". Eles se solidarizam com todas as línguas que falam ainda, marcadas em seus discursos pela assimilação à criança, à mulher, aos iletrados, à loucura, aos anjos ou ao corpo. [...] eles insinuam em toda parte um "extraordinário": são citações de vozes - vozes cada vez mais separadas do sentido que a escrita conquistou, cada vez mais próximas do canto ou do grito. Seus movimentos atravessam então uma economia escriturária e se extinguem, parece, quando ela triunfa. Assim a figura passante da mística nos interroga ainda sobre o que nos sobra da palavra. (CERTEAU, 2005, p.19).

primeira tem sua origem nos anos de 1940, a segunda surge nos anos de 1970 e a última começa por volta dos anos de 1990.

5 Literalmente, iniciar nos mistérios. (BAYLLY, 1935, p. 580).

6 Sobre esses últimos, estado alterado de consciência, privação do sono, laceração da carne, jejuns, histeria, dentre outros, vale a pena ver o estudo de Kroll e Bachrach (2005). Na contracapa do livro, lemos: "The Mystic Mind is the result of a fascinating collaboration between a medieval historian and a professor of psychiatry, applying modern biological and psychological research findings to the lives of medieval mystics and ascetics. This illuminating study examines the relationship between medieval mystical experiences, and the religious practices of mortification of the body." O livro traz um apêndice com uma análise estatística sobre os tipos de alterações corporais e mentais, onde as classifica e mostra sua distribuição entre homens e mulheres, seus períodos históricos, suas classes sociais, o papel que ocupam na igreja, enfim, um estudo interessante para quem queira estudar a mística sob o aspecto dos fenômenos corporais e mentais que afetam alguns místicos e místicas. 
As línguas, os discursos, as vozes, a escrita, a economia escriturária, tudo isso faz parte da palavra que reverbera em meio ao silêncio e que exige dos estudiosos mais do que uma simples análise dos textos místicos, exige uma atitude de ausculta que deve levar em conta o contexto dessas escritas com tudo o que este representa. Nesta direção, é preciso atentar para o horizonte da religiosidade ${ }^{7}$, pois este é o lugar de onde os textos místicos, ao menos a sua maioria, falam, e também é preciso ter uma atitude de acolhimento em relação ao estilo adotado, sobretudo pelas místicas, uma vez que foge ao estilo de um tratado filosófico, pelo menos no que tange aos textos filosóficos gestados no confronto com os textos poéticos em que temos conhecimento dos mitos, e uma determinada forma de fazer filosofia que se segue a partir dai ${ }^{8}$.

Este lidar com os textos, por sua vez, faz um outro estudioso da mística, Bernard McGinn, asseverar (o que reforça a nossa ideia) que, mesmo levando em conta que os textos místicos são a expressão de uma experiência, o que nós estudamos são esses textos místicos e o seu lugar numa determinada tradição. Mas, mesmo assim, prossegue, devemos nos perguntar o que é a mística, pois "como qualquer definição simples de um fenômeno complexo e controverso parece utópica." (MCGINN, 2012, p. 16). Desta forma, ele opta por fornecer um sentido sobre a sua compreensão acerca do termo mística, discutindo-o sobre três tópicos: "mística como parte ou elemento da religião, mística como um processo ou modo de vida e mística como uma tentativa de expressar uma consciência direta da presença de Deus" (Ibidem, p. 16).

Já Maria Clara Bingemer (2010), em um estudo sobre mística e filosofia, se questiona sobre a pertinência de tal relação e se é possível pensar e universalizar uma experiência irredutivelmente pessoal, como é o caso da mística, por parte de alguém que quer pensá-la sem, entretanto, ter tido tal

\footnotetext{
7 Não estamos desconsiderando aqui os místicos ateus, nem uma parte dos místicos e das místicas contemporâneas que produziu seus textos fora do ambiente religioso. Apenas não são esses os estudados aqui, mas a mística desenvolvida na Idade Média. De qualquer forma, sobre a existência de uma mística não religiosa, escreve Capelle (2003, p.86): "Infine, la visione rigorosa della finitudine e della sua consistenza transcendentale obbliga a riconoscere la pertinenza di una mistica non religiosa, intendo con ciò uno slancio in un abbandono unificante e sereno al mistero dell'esere sempre già dato che supera il mio esere e che costituisce il mio ambiente, il mio elemento, il mio destino".

8 Sobre isso, veja-se nosso estudo NOGUEIRA, 2016, p. 11-26.
} 
experiência. A estudiosa escreve ainda que, se esta experiência pode ser universalizada e pensada, cabe ainda a questão do lugar da hermenêutica no ato de pensá-la. De qualquer maneira, compreende a mística como um conhecimento, cuja

aparição, portanto, se dá no âmbito de uma questão especificamente filosófica: a questão da transcendência e a experiência que dela faz o sujeito humano, percebendo-se como constitutivamente autotranscendente, apesar de sua finitude e contingência. (BINGEMER, 2010, p. 40-41).

É a questão da transcendência, portanto, que aproxima mística e filosofia. Lembremos que Hegel, em sua Introdução à história da Filosofia, afirma que a religião e a filosofia se aproximam (a mística pode ser entendida aqui também), pois têm como objeto o infinito, o que não é da ordem do terreno ou do mundano (HEGEL, 1991, p. 39) ${ }^{9}$. Nesta mesma direção Marco Vannini (2007, p. 15) escreve, ao fazer referência à mística: “[...] trata-se, com efeito, de filosofia no sentido mais real e profundo [...]”, complementando que é uma experiência do espírito há tempos perdida pelo homem contemporâneo $^{10}$. Ora, no que apresentamos até aqui, é possível refletir um pouco sobre a complexa relação entre mística e filosofia, repensando os dois aspectos colocados no início desta parte do artigo: a relação da mística com a religiosidade e o estilo da sua escrita.

No que diz respeito à relação da mística com a religiosidade, isto parece ser um dos motivos assumidos por uma determinada tradição filosófica que rejeita a mística. Mas, mesmo refletindo sobre tudo o que esta relação pode representar no confronto com o saber filosófico, chamamos a atenção para alguns aspectos do saber místico. Primeiro, a mística, de uma maneira geral, tem realmente uma forte ligação com a religiosidade, mas não, necessariamente, com a religião entendida no sentido dado pela instituição religi-

\footnotetext{
9 Nesta mesma obra o filósofo alemão dedica uma parte para dizer que o elemento religioso deve ser excluído da história da filosofia. No entanto, não nos cabe aqui fazer uma reflexão sobre o pensamento hegeliano. Só o citamos mais acima para ilustrar e reforçar que a ideia da transcendência ocupa um lugar importante também na filosofia e não apenas na religião.

10 Neste livro, Vannini aborda as relações entre mística e filosofia em filósofos e filósofas como Mestre Eckhart, Nicolau de Cusa, Ibn 'Arabî, Hegel, Nietzsche, Marguerite Porete e Simone Weil. O capítulo sobre Marguerite Porete abre com a seguinte afirmação: "Tutto quel che concerne - nell'essenziale - filosofia, teologia, mística, si trova già presente e per così dire concentrato, all'inizio della storia dell'Occidente, in Platone." (VANNINI, 2007, p. 20).
} 
osa. Segundo, a mística se mostra, na maioria das vezes, como crítica desta instituição. Ora, até onde sabemos, a crítica é uma característica intrínseca à própria filosofia e, neste sentido, para além da transcendência, mística e filosofia se encontram também no terreno da crítica. Terceiro, se a arrogância filosófica se pauta na ideia de que é necessário ver o todo, mesmo sabendo não ser possível alcançar isto plenamente, a análise da religião, ou do ser humano na sua relação com o sagrado (para sermos mais rigorosos do ponto de vista da mística) não deve ficar de fora das ambições de quem filósofa. Por fim, a mística bem pode ser uma resposta à crise da metafísica marcada, dentre outras coisas, por uma linguagem apofântica ${ }^{11}$.

Seguindo nesta perspectiva, passemos ao estilo do texto místico. Ora, as críticas encontradas nos textos místicos, seja à religião, seja à metafísica, seja a uma determinada forma de se estar no mundo, podem ser entendidas também como uma crítica à linguagem, afinal como escreve Yunes (2010, p. 76-77): "No espaço místico tudo é impronunciável, a língua cala e o silêncio fala num esforço de violência contra a linguagem, investindo contra os limites do interdito; [...]." Logo, os textos místicos não se apresentam como tratados filosóficos, no sentido entendido por toda uma tradição que vai, no mínimo, de Aristóteles até Hegel. Assim, pensando mais especificamente no que estamos chamando de mística feminina medieval, os textos com os quais lidamos são transgressores da própria linguagem, posto que investem contra os limites do dizível e, para tanto, são construídos não apenas por uma linguagem apofática, mas também por uma linguagem que é apresentada em versos, canções, ditos, feitos, aforismos, enfim, uma linguagem expressa por metáforas, paradoxos, sinestesias, oxímoros, em suma, por recursos estilísticos que visam investir contra os limites da própria linguagem. Por isso, não é à toa que Certeau (2005, p. 114) assevera que a mística nomeia uma proliferação léxica de um determinado experienciar que designa, por sua vez, "maneiras de fazer" ou "maneiras de dizer" que são, ao mesmo tempo, “maneiras de praticar a língua”. Logo, não precisamos ir muito longe para entender porque uma dada tradição filosófica a rejeitou, pois a entendeu como ilógica e sem sentido, ou seja, rigorosamente não a entendeu.

11 Veja-se sobre isso, MICHELAZZO, 2012, p. 262-279. 
Ora bem, o que queremos dizer, como já afirmamos em outro estudo nosso (NOGUEIRA, 2016), é que não há nada de errado com esse modo de fazer filosofia, isto é, por meio de tratados sistemáticos, com argumentações claras e precisas, exceto a arrogância de se pensar ser esta a única forma aceitável de fazê-la, ao ponto de não conseguir enxergar nos textos místicos uma racionalidade e uma lógica que lhe são bem próprias, é verdade, mas que não deixam de fazer sentido. Logo, encerramos esta primeira parte do nosso artigo com uma citação de Eduardo Losso que nos parece resumir bem o que aqui tentamos expor, mas que aponta para uma relação muito mais abrangente do que apenas a existente entre mística e filosofia. Escreve Losso, no prefácio feito ao livro Narrativas místicas: antologia de textos místicos da história do cristianismo.

O estudo da mística abre novos horizontes para uma série de problemas, complexifica falsas soluções teóricas e introduz nelas questões pouco ou nada levadas em consideração, na Antiguidade, na Idade Média ou na Modernidade, na filosofia, na teologia ou na literatura. As relações entre o racional e o irracional, dogma e heresia, tradição e inovação, conservadorismo e modernismo, metafísica e desconstrução ficam muito mais ricas e sutis quando o objeto em questão está dentro do universo da mística. Ela desafia religiosos e ateus, estetas e políticos, direita e esquerda, cristãos e outras religiões, e os obriga a considerar o seu oposto, perceber os limites de sua posição e saber dialogar sem preconceitos (LOSSO, 2016, p. 21).

\section{A mística medieval}

A mística medieval, ao contrário do que se possa pensar, não é um pensamento uniforme e, portanto, passível de ser classificada em uma única escola de pensamento. A própria classificação por escolas já é algo problemático quando se pensa a mística na Idade Média, mesmo nos limitando, por exemplo, ao Ocidente Cristão. De toda forma, ainda que este artigo possua uma delimitação temporal e religiosa, é importante informar que a mística não nasce nem morre na Idade Média Ocidental. Isto é, já encontramos textos místicos na Antiguidade Oriental e Ocidental, assim como são encontrados na Modernidade e na Contemporaneidade. Por outro lado, quando nos referimos à mística oriental, talvez nada mais estejamos fazendo do que olhar para o Oriente com a nossa visão de mundo ocidental e consequente- 
mente com nossas categorias. Apenas para dar um exemplo dessa complexidade, Suzuki (1955) afirma que o Zen não é mística, pois esta, tal qual é entendida no Ocidente, geralmente começa com uma antítese e termina com uma unificação ou identificação (humano-divino) e isto é fruto de uma concepção dualista da vida e do mundo ${ }^{12}$.

Pensando ainda em termos de Oriente-Ocidente, Tabuyo (2016), na introdução que faz à sua tradução das lições de uma mística do século VIII, Râbi'a al-'Adawiyya (sufi muçulmana), alerta-nos sobre a tentação de nos apropriarmos daquilo que não nos pertence, reduzindo-o aos nossos esquemas e categorias, fazendo com que percamos qualquer possibilidade de compreensão disto que nos apropriamos. Assevera, assim, que Râbi'a não é uma mística cristã e que não devemos enquadrá-la em categorias que lhes são estranhas, pois até mesmo o uso do termo mística pode encobrir ou usurpar do sufismo aquilo que é próprio da religião muçulmana que, por sua vez, tem suas próprias chaves de leitura que não são intercambiáveis (TABUYO, 2016, p. 10). Desta forma, mesmo quando encontramos semelhanças entre Rabi'a al-'Adawiyya e Marguerite Porete, por exemplo, como as ideias de aniquilamento do eu, da pobreza, do abandono, do desejo, mesmo assim, as aproximações devem aparecer com cautela e com a preservação dos lugares de onde essas místicas falam/escrevem.

Mas não pensemos que ficando apenas no Ocidente as interpretações sejam unívocas ${ }^{13}$. Aliás, é interessante perceber em meio a tantos místicos e místicas ou, mais precisamente, em meio a tantos textos escritos por estes e estas, que apenas um determinado grupo recebe o nome de escola: a que se desenvolve na Alemanha, nos séculos XIII e XIV, “às margens do Reno", e

12 E complementa: "If there is an antithesis, Zen accepts it as it is, and makes no attempt to unify it. Instead of starting with dualism or pluralism, Zen wants us to have a Zen-experience, and with this experience it surveys a world of suchness. [...] Zen therefore is not mysticism, although there may be something in it reminding one of the latter. Zen does not teach absorption, identification, or union, for all these ideas are derived from a dualistic conception of life and the world.”. (SUZUKI, 1955, p. 74 e 81).

13 Um exemplo desta diversidade pode ser lido no seguinte passo do estudo de NEWMAN (2016, p, 591): "Mechthil of Hacheborn, Angela of Foligno, and Marguerite Porete were exact contemporaries who differed in language, social status, and modes of religious life; their books diverge no less in genre, modes of production, and posthumous destinies. Thus comparing them can provide a way to contextualize the radical idea of annihilation, which Bernard McGinn links expressly with women, as it took shape within the varied contexts of their authorship." Apesar das diferenças apontadas por Newman, como podemos perceber, ela destaca que, para McGinn, há um traço distintivo comum não só entre essas três mulheres, mas às mulheres místicas, de uma maneira geral, que é o conceito de aniquilação. 
por isso mesmo recebe o nome de mística renana ou de escola renana. Alain de Libera (1994), por exemplo, lhe dedica um livro onde afirma que seu objetivo é redescobrir as categorias medievais e que esta mística representa um momento fundador na história da filosofia. Já McGinn, no seu livro The Harvest of Mysticism in Medieval Germany, dedica toda a segunda parte da obra a Eckhart (principal representante daquela escola) e a seus alunos (Suso e Tauler). Ali McGinn expõe as dificuldades para o uso do termo mística renana, alegando, dentre outras coisas, que muitos o fazem por causa da localização geográfica, mas os que assim a denominam colocam, por exemplo, os místicos holandeses, como Ruusbroec, também nesta denominação (MCGINN, 2005, p. 86) ${ }^{14}$.

Já um outro estudioso da mística, o suíço Alois Haas, ao falar sobre a história da mística renana, afirma que nela não deveria faltar o nome do Cardeal, e grande homem da igreja, Nicolau de Cusa, e não pelo fato de o filósofo alemão ter demonstrado com a sua vida a existência do fundamento de uma forma mística, mas sim por ele, no contexto do seu pensamento, ter feito, explicitamente, da teologia mística objeto da sua reflexão (HAAS, 2004, p. 262). No mesmo direcionamento, McGinn, num outro texto, reconhece a importância de Nicolau de Cusa na história da mística, entretanto, afirma que esta importância ainda não foi apreciada como deveria. Reflete sobre o texto De visione dei do filósofo alemão e acrescenta, com base neste, que suas ideias não se enquadram na mística vernácula, frequentemente de caráter pessoal e emocional, nem tampouco no que se poderia chamar de uma forma de mística escolástica, isto é, organizada em tratados e manuais. Desta forma, concordando com Haas, o estudioso norte-americano diz que a mística feita por Nicolau de Cusa é uma espécie de resumo bem estruturado da teologia mística que se posiciona sobre certos números de problemas discutidos à época (MCGINN, 2006, p. 158).

Permanecendo apenas no Ocidente Medieval, portanto, percebemos que a discussão em torno da mística e de suas possíveis escolas de pensa-

14 Para destacar, sobretudo a mística eckhartiana, ele propõe o uso de outra expressão, como podemos ler no excerto que segue: "I propose that the mysticism of the ground is an equally useful tool for understanding the message of Eckhart and many who were influenced by him. To be sure, Eckhart and his followers treat many mystical themes, both traditional and innovative, but grunt provides a useful lens to bring into focus distinctive elements of their mystical thought." (MCGINN, 2015, p. 87). 
mento - mística renana ou especulativa, afetiva, cisterciense, nupcial etc. envolve uma série de outros elementos para além da ideia de experiência. Esses outros elementos dizem respeito ao modo como os textos são organizados, que lugares ocupam dentro de uma determinada tradição de pensamento, se é antecedido por visões ou não, se ocorre com ou sem fenômenos (sejam corporais ou extraordinários), se o que se entende por teologia místi$\mathrm{ca}^{15}$ pode ser compreendido como a própria mística, em síntese, muitas outras questões podem e devem ser colocadas quando se estuda a mística. No entanto, nosso objetivo é pensar sobre a possibilidade de categorizar a mística feminina medieval e consideramos que o exposto, embora não esgote a discussão, é suficiente para mostrar um pouco das dificuldades quando se aborda a mística medieval.

\section{Mística feminina medieval}

Como observamos na seção anterior, a falta de um lugar para a mística $^{16}$ dificulta muitas vezes a sua compreensão. Quando se trata, então, de mística feminina medieval, a dificuldade aumenta porque é necessário desconstruir, no mínimo, três preconceitos: a mística como um saber destituído de lógica; o feminino como destituído de razão; e a Idade Média como destituída de luz (e tudo o que isto pode representar) ${ }^{17}$. De toda forma, importa perceber que a expressão mística feminina atribuída às mulheres na Idade Média é uma categoria citada por diferentes estudiosas e estudiosos quando se debruçam sobre os textos daquelas mulheres e assumem feições diferentes quando lidas, por exemplo, pela crítica feminista, pela teologia, pela história, pela literatura, pela filosofia, enfim, por movimentos que, na nossa compreensão, não deveriam ser excludentes, mas complementares e, desta forma, é esta a leitura que fazemos.

\footnotetext{
15 Como observa McGinn (2006, p. 143): "La Théologie Mystique de Denys est un text clef pour Nicolas de Cues, en particulier en rasion de la manière dont is fait ressortir la caractere absolutement invisible de Dieu." E, acrescentamos nós, a Teologia mística de Dionísio, pseudo-areopagita (Séc. VI) é não apenas um texto, é uma maneira de dizer Deus que será fundamental para todo o desenvolvimento da mística que lhe é posterior. Veja-se sobre a obra de Dionísio, ANDIA, 2006. Para recepção do texto dionisíaco e uma interpretação mais afetiva do que intelectiva da mística, veja-se HUGO DE BALMA, 1995, 1996.

16 Veja-se sobre isto MICHELAZZO, 2012.

17 Uma tentativa de desconstrução desses preconceitos foi feita no nosso estudo NOGUEIRA, 2020, p. 76-90.
} 
Vejamos, então, algumas definições possíveis da mística feminina medieval.

Kurt Ruh em sua obra Storia della Mistica Occidentale: mistica femminile e mistica fracescana delle origini ${ }^{18}$ ) escreve: "A mística feminina inclui textos que foram escritos por mulheres ou transmitidos por estas [...]; no entanto, também inclui retratos biográficos de visionárias ou mulheres que estiveram na vida da graça.” (RUH, 2002, p. 19). McGinn, por sua vez, mesmo sendo mais cauteloso com a expressão mística feminina, preferindo nova mística, assevera que "Nada é mais surpreendente a respeito da nova mística [...] do que a importante função que as mulheres assumem, em termos de narrativas hagiográficas e de textos produzidos pelas próprias mulheres.” (MCGINN, 2017, p. 34). Já a estudiosa Lieve Troch, ao abordar a mística feminina, afirma que "A 'mística', tal como é praticada por mulheres, é caracterizada por uma linguagem alegórica, uma linguagem de visões, uma linguagem poética, um modo de vida e espiritualidade, mas também por uma reformulação teológica da divindade." (TROCH, 2013, p. 3). Por fim, as estudiosas espanholas, Victoria Cirlot e Blanca Garí, afirmam que, desde o século XII até o século XV, “[...] a escrita mística feminina se constrói multiforme e diversa. Mas em sua diversidade há algo que a unifica e permite reconhecê-la; algo que, como um eco constante, repete sempre sua chamada de pôr em palavras a experiência." (CIRLOT e GARÍ, 1999, p. 14) ${ }^{19}$.

Atentemos para o que há em comum entre os estudiosos citados (de diferentes áreas, filologia, filosofia, teologia, ciências da religião e literatura), apesar da existência de algumas divergências que dizem respeito às perspectivas que cada um assume nas suas pesquisas e sobre as quais não entraremos em detalhe aqui. O que converge nas referências acima é o reco-

\footnotetext{
18 O título original do livro de Ruh é Geschichte der abendländischen Mystik. II. Frauenmystik und Franziskanische Mystik der Frühzeit.

19 Da nossa parte, como mostramos em um estudo (2018, p. 132-152), a mística feminina medieval pode ser caracterizada por uma produção textual feita por mulheres, apresentando muitas vezes transgressões e veiculando formações identitárias, revelando também as relações de poder no conturbado e rico período do medievo (em torno dos séculos XII ao XV). Logo, não é exagero se falar de um forte movimento feminino na Idade Média que tinha como características (mesmo considerando as exceções), dentre outras, o uso da língua vernácula, a fusão do humano com o divino na união das instâncias afetivas e intelectivas; o uso paradoxal da linguagem, com apelos à linguagem simbólica; a forte influência da literatura cortês do século XII, apresentando, talvez por isso, uma linguagem marcada pelo erotismo e a ausência de uma formação escolar, já que as místicas medievais, ao contrário dos místicos, não passaram pelas Escolas/Universidades.
} 
nhecimento de todos e de todas da existência de uma produção escrita feita por mulheres. Logo, seja dando um peso menor à experiência (McGinn), seja reconhecendo a importância do elemento afetivo (Ruh), seja, numa leitura mais feminista, destacando a auto-definição, a auto-representação e a auto-autorização das mulheres medievais (Troch) ou, ainda, enfatizando a experiência individual e sua posterior necessidade de escrita (Cirlot e Garí), o fato é que tivemos no Medievo um grupo bastante considerável de mulheres que ousou colocar por escrito suas experiências e suas reflexões sobre o divino ao ponto de alguns considerarem o século XIII, onde houve um ápice deste movimento, como o século da mística feminina. No entanto, o que está sendo chamado de mística feminina passa longe de ter sido um movimento homogêneo, uniforme, unívoco e linear. Como tão bem expressou Ruh (2002), a impressão que a mística feminina causa é a de um mundo colorido, exoticamente fascinante, rico de tensões e até bizarro.

Todos estes adjetivos dizem muito da mística feminina desenvolvida na Idade Média, sobretudo a riqueza de suas tensões. McGinn chega a se questionar sobre a possibilidade de discernir uma mística distintiva das mulheres, ou seja, uma mística tipicamente feminina. Assevera que a resposta não se dá de forma simples, mas quer estabelecer diretrizes metodológicas para sua investigação, sobretudo no que diz respeito aos perigos que devem ser evitados. Consideramos que as diretrizes metodológicas propostas pelo estudioso americano nos ajudarão a refletir melhor sobre uma possível categorização da mística feminina e, assim, nos dedicaremos agora ao que McGinn escreve na sua monumental obra sobre a mística ocidental. Ali ele coloca quatro diretrizes metodológicas que serão seguidas na sua análise e que nos servirão de norte aqui. São elas: 1. Evitar generalização e essencialização indevidas; 2. Evitar privilegiar o presente; 3. Estar atento à perspectiva de gênero do documento investigado; 4. Levar em conta as formas de linguagem e modos de representação encontrados nos textos místicos. (MCGINN, 2017, passim).

A primeira das máximas orienta a não generalização no que diz respeito à mística feminina, ou seja, devemos ter discernimento, como já apontamos, de que os textos produzidos pelas mulheres medievais, em relação à mística, abarcam um período de tempo que vai do século XII ao século XV, 
logo, estão inseridos nos seus respectivos contextos e esses se refletem nas suas formas de expressão. Para McGinn, "é difícil imaginar que poderia haver uma forma única de mística característica de todas as mulheres, e só de mulheres (Ibidem, p. 34-35, itálico do autor). Também não acreditamos nessa forma única, mas, mesmo levando em conta toda as diferenças, nos inclinamos a pensar que é possível encontrar nas semelhanças dos textos das escritoras ou autoras medievais elementos que acenam para a possibilidade de pensar uma mística propriamente feminina. Ao longo do seu livro, McGinn mostra com muita propriedade que alguns homens fizeram uma mística muito semelhante à das mulheres, mas afirma, em várias partes do seu texto, que determinadas características se dão prioritariamente, e na sua maioria, nos escritos femininos. Logo, é esta forma prioritária e o seu volume (a maioria se dá em textos de mulheres) que nos inclina a pensar numa mística propriamente feminina, embora ainda tenhamos muito o que pesquisar.

A segunda máxima diz que devemos evitar privilegiar o presente e, neste sentido, McGinn, antes de explicar a sua diretiva, mostra que, em parte, a redescoberta das mulheres místicas medievais foi impulsionada pelo feminismo contemporâneo e também pela teologia feminista. Ele afirma que não há nada de errado nisso, mas tal leitura pode incorrer em alguns perigos, como, por exemplo, a do anacronismo, posto que as nossas inquietações ou perguntas contemporâneas não são as mesmas que instigaram os místicos medievais. Também concordamos com ele, mas não podemos esquecer que por mais que a mundividência medieval deva ser respeitada, as nossas inquietações são presentes e se esses textos nos espantam e nos tocam, ao mesmo tempo, é porque as inquietações das mulheres medievais nos ajudam a pensar o nosso mundo também. Neste sentido, a leitura feminista contemporânea, assim como qualquer outra leitura que não seja feminista, corre os seus riscos, afinal é daqui que falamos. De toda forma, como trabalhamos com textos, devemos levar em consideração que "[...] as definições sucessivas e a hermenêutica das fontes devem ser constantemente examinadas criticamente" (TROCH, 2013, p.4) sem perdemos de vista o horizonte em que foram escritos com todos os seus fenômenos, gostemos ou não deles.

A terceira máxima de McGinn diz respeito à necessidade de estarmos atentos à perspectiva de gênero do documento investigado. Isso nos pa- 
rece fundamental, mas o estudioso chama-nos a atenção para dizer que "grande parte daquilo que sabemos sobre as mulheres místicas medievais provém da pena de seus admiradores masculinos" (MCGINN, 2017, p. 36). Ora, nos parece que, para tal afirmação, ele se pauta muito mais nas hagiografias, feitas realmente pelos admiradores dessas mulheres, do que nos textos que elas produziram, seja escrevendo do seu próprio punho, seja ditando para um secretário. Logo, mesmo dando um exemplo clássico para ilustrar a diferença de uma mulher apresentada por ela própria e posteriormente por um conselheiro homem, como foi o caso de Beatriz de Nazaré ${ }^{20}$, e mesmo afirmando que a partir do século XIV algumas mulheres começaram a produzir hagiografias, ele permanece muito voltado para as vitae e quando delas sai é para mostrar a cooperação que houve entre homens e mulheres na produção dos textos femininos.

Bem, duas observações devem ser feitas aqui. A primeira é que nas nossas investigações nunca negamos a cooperação que houve entre as mulheres místicas medievais e os homens. Pelo contrário, e apenas para ilustrar, a relação dos religiosos franciscanos, dominicanos e cistercienses com as beguinas, por exemplo, foi fundamental para a escrita e divulgação dos seus textos. Como afirmam, Cirlot e Garí (1999), a espiritualidade feminina, sobretudo a partir do início do século XIII, encontrou defensores no interior das hierarquias eclesiásticas e, complementam, "enquanto as mulheres necessitavam escrever, os homens necessitavam ouvi-las" (Ibidem, p. 37). Isso para não falarmos das cooperações mais explícitas como foram os casos de Marie de Oignies e Jacques de Vitry, Elisabeth von Schönau e Ekbert ou mesmo Hildegard von Bingen e Volmar. Logo, a cooperação entre homens e mulheres não anula a ideia de tentarmos ver na mística feminina textos que nos falam, muitas vezes, em primeira pessoa ${ }^{21}$.

A segunda observação se refere às vitae, quer dizer, nem todas as mulheres místicas medievais tiveram uma e, a título de ilustração, citamos

\footnotetext{
20 Já falamos sobre isso no nosso artigo NOGUEIRA, 2017, p. 150-160.

21 Sobre esta primeira pessoa, podemos ler: "Es absolutamente imprescindible sacarse el velo romántico para aproximarse a la realidad de esa primera persona del mundo medieval, pues si pensamos que en ella encontraremos al sujeto que de un modo directo expressa todo aquello que le acontece convencido de su importancia, sin duda caeremos en el error. Pero tampoco nos parece lícito pensar vacía a esa primera persona, considerarla como una simple retórica que en absoluto tiene que ver nin con la realidad de la persona, ni con su experiencia como individuo." (CIRLOT e GARÍ, 1999, p. 31).
} 
Hadewijch da Antuérpia e Marguerite Porete. Assim, o que sabemos da vida de ambas as beguinas nos vem da sua própria pena e é encontrado nas suas obras. Em Hadewijch, graças às Cartas e às Visões, podemos saber um pouco da sua vida, embora os Poemas ou Canções também sejam reveladores, sobretudo, da sua formação. Já em Marguerite, o seu único livro, pelo menos que nos tenha chegado, mostra-nos um pouco da sua vida, inclusive as perseguições sofridas que, como sabemos, acabaram por levá-la à fogueira em 1310. Dois dados curiosos em $O$ espelho das almas simples de Porete chamam a nossa atenção, o primeiro é quando ela coloca em meio às personagens do livro uma personagem(?) chamada "Autora". Isso ocorre no Pró$\log o$ e se repete nos capítulos 111 e $112^{22}$. Já no capítulo 52 quando Porete usa a expressão preciouse marguerite, numa fala da personagem Amor, isso pode indicar, ainda que discretamente, a assinatura da sua obra, ou seja, ela pode ter colocado ali uma marca autoral. Logo, embora tenha havido uma cooperação entre homens e mulheres e ainda que muitos homens tenham escrito sobre a vida e a obra de muitas mulheres, na nossa compreensão é perfeitamente possível pesquisar muitas dessas mulheres a partir do gênero feminino que escreve, e o que isso representa na Idade Média, sem deixar de refletir na nossa Contemporaneidade algumas dessas ideias.

A quarta e última diretriz metodológica de McGinn pode ser extraída da seguinte afirmação: “A questão da função das mulheres e das complexidades de gênero é inseparável da terceira área principal que merece comentário - a das formas de linguagem e modos de representação encontrados nos textos místicos" (MCGINN, 2017, p 39). Ele afirma que tem insistido que o objeto de estudo não é a experiência mística em si, mas o que se produz sobre ela, seja a escrita, seja a imagem. Fiquemos, pois, com a escrita, posto que é esta que estudamos quando pensamos a mística feminina medieval. Ora, mesmo reconhecendo que depois do ano 1200 a língua escrita da mística sofre mudanças, sendo assumida por muitos, sobretudo as mulheres, a sua forma vernácula e não mais o latim e, apesar de reconhecer que essa

\footnotetext{
22 Na versão do CORPVS CHRISTIANORVM, editado por Guarnieri e Verdeyen, encontra-se respectivamente "L'Ame e L'Acteur". Aparece também a frase, “que escreve o livro", tanto no francês quanto no latim: "dit l'Ame qui ce livre fist escrire" e "dicit Anima quae hunc librum scribi fecit". Já nos capítulos 111 e 112 "Autora" não aparece na edição do CORPVS CHRISTIANORVM, mas na tradução para o português do Brasil feita por Sílvia Schwartz, 2008.
} 
mudança trouxe notáveis configurações novas, McGinn, com a erudição que lhe é peculiar e o rigor de informações importantes que nos oferece, conclui:

Mas definir a mística "real" primariamente como a mística "experiencial" e visionária encontrada nos textos em vernáculo da Idade Média tardia, é empobrecer a riqueza da tradição mística ocidental e impedir, em vez de ajudar, na tarefa de tentar entender a própria mística nova. Sua novidade real é constituída nos termos do seu diálogo com a tradição mais antiga (Ibidem, p. 46-47).

Reflitamos por partes. Primeiro, quando pensamos na mística feminina medieval, constituída em sua maior parte por textos em língua vernácula, o que o próprio McGinn reconhece, não estamos contrapondo de forma simplista a mística produzida pelos homens e a mística realizada pelas mulheres, até porque sabemos que houve alguns homens que se expressaram em vernáculo e algumas mulheres que se expressaram em latim. Segundo, não estamos atribuindo um juízo de valor, pois em nenhum momento dos nossos textos afirmamos que a mística feminina em língua vernácula é superior à mística masculina expressa em latim. Terceiro, também não estamos colocando a mística visionária ou experiencial em língua vernácula como mais real do que a tradição que lhe antecede. Logo, concordamos com Bernard McGinn quando ele afirma haver um diálogo desta mística feminina feita em vernáculo com uma mística de tradição mais antiga feita em latim. Só não estamos muito seguros de este diálogo ser uma novidade.

Mas voltemos à questão da linguagem. Kurt Ruh (2002) afirma que se mudam os conteúdos e as formas dos discursos místicos, muda-se também a forma do texto, e considera a passagem do latim para a língua vulgar um passo importante na história da mística desenvolvida no Ocidente. Reflete também sobre as razões dessa mudança e, assim como McGinn, reconhece que as mulheres, de uma maneira geral, estavam privadas da educação escolástica superior. Logo, o que restava às mulheres era a língua não escolar, ou seja, suas línguas maternas, embora tenhamos conhecimento que algumas dessas mulheres sabiam latim e outras línguas além da vernácula. Mas é preciso acrescentar a essas línguas maternas os seus corpos (corpos femininos) que se articulam e fazem parte desta escrita, não apenas porque é bem característico de uma boa parcela das mulheres místicas medi- 
evais a linguagem erótica ${ }^{23}$, como também porque alguns fenômenos ocorrem na carne e são expressos por meio da linguagem. Assim, a definição de mística dada por Troch $(2013$, p. 4) tem sua razão de ser, afinal, como ela escreve: “A definição de 'mística' é dada usualmente a uma determinada forma e estilo de textos históricos, a saber, aqueles que compreendem visões, alegorias, metáforas e poesia em uma relação específica com o corpo."

Gostamos de dizer que são textos/mulheres ou mulheres/textos, uma vez que a escrita ganha corpo ou, como escreve Foucault (1992, p. 143), “a escrita transforma a coisa vista ou ouvida em forças e em sangue. Ela transforma-se no próprio escritor". No caso aqui, escritora ou escritoras, já que se trata de um número considerável de mulheres. Mais do que isto, de um número considerável de mulheres bastante conscientes do seu poder de escrever, como assinala Régnier-Bohler (1990, p. 536). Neste mesmo direcionamento, Cirlot e Garí (1999, p. 28) argumentam que somente uma necessidade imperiosa pode explicar a existência de um corpus textual que expressa a experiência mística. Lidamos, portanto, com necessidades (escrever), com desejos (a presentificação de Deus) e com textos cujas autoras se esforçam por equilibrar necessidades e desejos na busca humana de uma vivência ou reflexão que ultrapassa a mais extraordinária das linguagens, daí também a variedade dos gêneros literários que dali surgem. Como escrevem as estudiosas espanholas:

o aparecimento de uma atitude nova em relação ao indivíduo e seu sujeito que nasce no século XII e se vai intensificando ao longo do século XIII, encontrando para isso diversas soluções conforme os distintos âmbitos linguísticos e os gêneros literários (CIRLOT e GARÍ, 1999, p.33).

\footnotetext{
23 No entanto, como bem nos mostra McGinn, encontramos algo semelhante em alguns poucos homens, como por exemplo, Jacopone de Todi, um leigo erudito que tem uma conversão depois da morte da sua esposa em 1268. Dentre outras coisas, escreve o estudioso norte-americano sobre Jacopone: "Embora Jacopone soubesse latim, sua contribuição foi essencialmente em vernáculo e na forma poética. [...] Aqui Jacopone oferece um notável exemplo do iubilus, o irreprimível transbordamento de amor encontrado entre tantos místicos do século XIII, sobretudo entre as mulheres. [...]Essas trevas da mútua aniquilação, o duplo abismo de Deus e da alma (de fato, o mesmo abismo), leva Jacopone perto de um dos maiores temas especulativos da nova mística, tema este encontrado primeiramente entre as mulheres místicas [...].” (MCGINN, 2017, passim, destaques nossos).
} 
Interessante observar que a escrita dessas mulheres surge como uma necessidade de vida. Em muitas delas lemos como escrever, mais do que importante, é necessário e fundamental, como já abordamos em outros estudos $\operatorname{nossos}^{24}$. Esta necessidade, por sua vez, passa não somente por uma escrita de $\mathrm{si}^{25}$, mas também pela constituição daquela que escreve, ou seja, as mulheres místicas medievais escreviam para expressar as suas experiências e reflexões e escreviam, igualmente, como uma forma de exercitar a autocompreensão, buscando, naturalmente, entender o que se passava com elas. Além disso, não podemos descartar a escrita de muitas dessas mulheres como um ato político, muito embora isso, talvez, não venha em primeiro plano $^{26}$. De qualquer modo, é preciso reconhecer que nos textos de muitas mulheres místicas, como Marguerite Porete, Mechthild von Magdeburg e Catarina de Siena, por exemplo, encontramos a insatisfação dessas autoras face ao momento em que vivem, sendo, inclusive, a crítica à instituição religiosa um tema recorrente.

Portanto, a última "diretiva" analisada por McGinn, que diz respeito à complexidade de gênero na sua relação com as formas da linguagem e seus modos de representação, nos parece um elemento importante para pensarmos a mística feminina medieval como apresentando um diferencial em relação à mística produzida pelos homens. Por mais que McGinn nos apresente homens que escreveram de forma semelhante às mulheres, sobretudo no que diz respeito a uma linguagem erótica, ele mesmo afirma em vários passos do seu livro que esta linguagem é mais marcante e predominante nas mulheres ${ }^{27}$, e esta predominância continua sendo um elemento importante

\footnotetext{
24 Como por exemplo, NOGUEIRA, 2015, p. 91-102.

25 Sobre este tema na Idade Média veja-se nosso estudo NOGUEIRA, 2020, p. 76-90 (op. cit.), e também LIMA e NOGUEIRA, 2020, 396-413 (op. cit.).

26 A este respeito, escreve Schwartz (2010, p. 115) sobre Porete, sugerindo uma ação política: "Ao falar em sus própria voz, no Mirroir des âmes simples et anéanties [o Espelho das almas simples e aniquiladas], Marguerite Porete desenvolve um processo místico que resiste ao masculino, ao latim e ao escolástico, ao domínio das instituições eclesiásticas, ao sacerdotal e mesmo à faculdade da razão. Por outro lado, privilegia o feminino, o vernacu lar, as qualidades de fé e amor, e o faz se apropriando de papéis masculinos. Talvez possamos de fato entender seu discurso e comportamento como políticos, já que sua voz foi literalmente emudecida por sua condenação e morte na fogueira inquisitorial." (SCHWARTZ, 2010, p. 115).

27 Para algumas comparações entre homens e mulheres da nova mística, com um acento que nos inclina mais a uma categorização da mística feminina, veja-se McGinn (2017, op. cit.), páginas 43, 47, 110,111, 139, 141, 181, 181, 197, 207, 208, 238, 239, 240, 241, 259 e 260.
} 
para nos inclinarmos a pensar uma mística feminina. Aliás, quando começa a expor o que ele chama de nova mística, logo depois de demostrar a mudança de atitudes que ocorre na relação entre mundo e claustro e, ao iniciar a exposição da segunda mudança, que tem a ver com a relação entre homens e mulheres no caminho místico, ele afirma: “A segunda mudança maior na mística da Idade Média tardia envolve o gênero: é somente depois de 1200 que as mulheres começam a assumir um lugar proeminente na tradição mística" (MCGINN, 2017, p.33). E continua, um pouco mais depois desta assertiva, que o surpreendente no que ele chama de nova mística é a função assumida pelas mulheres na produção dos seus textos.

Logo, ao nos determos nas diretrizes postas por McGinn e ao nos posicionarmos em relação ao que concordamos e ao que discordamos da leitura dele, não significa dizer que estamos afirmando com todas as letras que a espiritualidade feminina é diferente da espiritualidade masculina, embora, como já demonstramos em outro estudo quando citamos Schwartz, ela chama a atenção para a ideia de uma experiência feminina do divino, com características diferentes do modo como os homens vivem essa experiência. (LIMA e NOGUEIRA, 2020). De qualquer modo, não apenas porque ainda não nos debruçamos o suficiente sobre tal temática e também porque esta não é nosso foco aqui ${ }^{28}$, fiquemos para finalizar, e não necessariamente concluir, com a possibilidade de pensarmos a mística feminina como uma categoria de pensamento.

\section{Considerações finais}

Portanto, para pergunta que nos provocou, qual seja, o que é a mística feminina medieval? Uma categoria teológica, histórica? Ensaiamos uma tentativa de resposta afirmando que a complexidade da mística (seja ela de qualquer período histórico) nos obriga, se quisermos ter uma visão mais ampla, a analisá-la sob diferentes perspectivas. Assim, alguém da filosofia, por exemplo, não deixa de fazer uma análise filosófica pelo fato de incluir na sua perspectiva outros pontos de vista, como o literário, o histórico, o teoló-

\footnotetext{
${ }^{28}$ Como dissemos na Introdução, consideramos que os textos místicos femininos são bastante diferentes dos produzidos pelos homens e, assim, estamos falando de produção escrita e não necessariamente de espiritualidade, embora reconheçamos que esta produção expres sa, de algum modo, a espiritualidade.
} 
gico e tantos outros que possam contribuir na investigação que está sendo feita. Neste sentido, escolhemos o texto de McGinn, prioritariamente para a última parte deste artigo, não apenas por ser um estudioso clássico da mística, como também porque seus questionamentos nos tiram da nossa zona de conforto exatamente pelo fato de não concordamos com todas as suas linhas de investigação e também porque este "bom confronto" ajuda a ampliar a nossa visão sobre a mística feminina medieval. Desta forma, a mística feminina medieval pode ser categorizada como um conjunto de ideias, cujas diferenças não devem ser esquecidas, mas também, cujas semelhanças podem e devem ser problematizadas sendo, por isso, passível de uma análise crítica que caracteriza não apenas o saber filosófico, mas tantos outros saberes. Já para o problema de ser possível pensar um traço distintivo da produção mística feminina medieval daquela produzida pelos homens no mesmo período, acreditamos não ser possível ainda responder afirmativamente, mas nos inclinamos a uma resposta afirmativa que, entretanto, merece uma pesquisa mais ampla. De todo modo, qualquer investigação que seja feita sobre a mística feminina medieval deve levar em conta à necessidade de prestarmos atenção à perspectiva de gênero dos documentos sobre os quais nos debruçamos, afinal, é a partir deles que as mulheres místicas medievais falam.

Recebido em 09/12/2020 e aprovado em 28/02/2021

\section{Referências}

ANDIA, Ysabel de. Denys l'aréopagite. Tradition et metamorfoses. Paris: J. Vrin, 2006.

BAILLY, Anatole. Dictionnaire grec-français. Paris: Hachette, 1935.

BINGEMER, Maria Clara Lucchetti. "Mística e filosofia: a propósito de Simone Weil". In: PINHEIRO, Marcus Reis e BINGEMER, Maria Clara Lucchetti (Orgs.). Mística e filosofia. Rio de Janeiro: PUC-Rio, 2010, p. 35-50.

CERTEAU, Michel de. A fábula mística. Tradução Abner Chiquieri. Rio de Janeiro: Forense Universitária, 2015.

CIRLOT, Victoria e GARÍ, Blanca. La mirada interior. Escritoras místicas y visionarias en la edad media. Barcelona: Ediciones Martínez Roca, 1999.

DE LIBERA, Alain. La mystique rhénane. D'Albert le Grand à Maître Eckhart. Paris: Éditions du Seuil, 1994. 
FOUCAULT, M. A escrita de si. In: $O$ que é um autor? Lisboa: Passagens, 1992, p. 129-160.

HAAS, Alois Maria. Mystik im Kontext. München: W. F. Verlag, 2004.

HADEWIJCH DE AMBERES. Flores de Flandes. Cartas. Visiones. Canciones. Tradução de Carmen Ros y Loet Swart. Madrid: BAC, 2001.

HEGEL, Georg Wilhelm Friedrich, Introdução à história da filosofia. Tradução de Arthur Mourão. Lisboa: Edições 70, 1991.

HUGO DE BALMA. Théologie mystique. Traduction de Francis Ruello. Paris: Les Éditons du Cerf, 1995 e 1996 (Tome I, Sources Chrétiennes, nº 408 e Tome II, Sources Chrétiennes, $n^{\circ} 409$ ).

LIMA, Emanuelle Valéria Gomes de; NOGUEIRA, Maria Simone Marinho. "Marguerite Porete e a escrita de si: entre a literatura e a filosofia". Revista Ideação, n. 42, Julho/Dezembro, 2020, p. 396-413. Disponível em: http:// periodicos.uefs.br/index.php/revistaideacao/article/view/5007/4767. Acesso em: 2 dez. 2020.

LIMA VAZ, Henrique Cláudio de. Experiência mística e filosofia na tradição ocidental. São Paulo: Edições Loyola, 2000.

LOSSO, Eduardo. Prefácio ao livro Narrativas mística: antologia de textos místicos da história do cristianismo. BINGEMER, Maria Clara Lucchetti e PINHEIRO, Marcus Reis (Orgs.). São Paulo: Paulus, 2016, p. 9-24.

MCGINN, B. O florescimento da mística: homens e mulheres da nova mística: 1200-1350. Tradução Pe. José Raimundo Vidigal. São Paulo: Paulus, 2017. (Tomo III).

MCGINN, Bernard. As fundações da mística. Das origens ao século V. Tradução de Luís Louceiro. São Paulo: Paulus, 2012 (Tomo I).

MCGINN, Bernard. The Harvest of Mysticism in Medieval Germany. New York: The Crossroad Publishing Company, 2015.

MCGINN, Bernard. "Nicolas de Cues sur La Vision de Dieu". In: VANNIER, Marie-Anne (dir.). La naissance de Dieu dans l'âme chez Eckhart et Nicolas de Cues. Paris: CERF, 2006, p. 136-158.

MICHELAZZO, José Carlos. "Mística, Heresia e Metafísica". In: TEIXEIRA, Faustino (Org.). Caminhos da Mística. São Paulo: Paulinas, 2012, p. 261-279.

NEWMAN, Barbara. "Annihilation and Authorship: Three Women Mystics of the 1290s". Speculum, 91/3, July, 2016, p. 591-630. Disponível em: https://www.journals.uchicago.edu/doi/pdf/10.1086/686939. Acesso em: 10 set. 2020 . 
NOGUEIRA, Maria Simone Marinho Nogueira. "Marguerite Porete: A mística como escrita de si". Revista Graphos, João Pessoa, v. 22, n.3, 2020, p. 76-90. Disponível em: https://periodicos.ufpb.br/index.php/graphos/article/view/54125. Acesso em: 2 mai.2021.

NOGUEIRA, Maria Simone Marinho. "Escritoras medievais: transgressões silenciadas". In: BROCHADO, Cláudia e DEPLAGNE, Luciana. Vozes de mulheres da Idade Média. João Pessoa: Editora UFPB, 2018, p. 132-152.

NOGUEIRA, Maria Simone Marinho. "Beatriz de Nazaré (1200-1268) e Os sete modos do Amor". Revista Graphos, João Pessoa, v. 19, 2017, p. 150160. Disponível em: https://periodicos.ufpb.br/index.php/graphos/article/ view/37751. Acesso em: 17 mar. 2020.

NOGUEIRA, Maria Simone Marinho. "Filosofia e Mística - Entre o que não se diz quando se fala e o que se diz quando se cala". In: NOGUEIRA e SILVA, Reginaldo Oliveira (Orgs.). Pequenos ensaios sobre grandes filósofos. EDUEPB: Campina Grande, 2016, p.11-26.

NOGUEIRA, Maria Simone Marinho. "Mística Feminina - Escrita e Transgressão". Revista Graphos, João Pessoa, vol. 17, n 2, 2015, p. 91-102. Disponível em: https://periodicos.ufpb.br/ojs/index.php/graphos/article/view/ 27290. Acesso em 25 jul. 2020.

PORETE, Marguerite. $O$ espelho das almas simples e aniquiladas e que permanecem somente na vontade e no desejo do amor. Tradução e notas de Sílvia Schwartz. Petrópolis: Vozes, 2008.

PORETE, Marguerite. Le mirouer des simples ames. GUARNIERI, Romana y VERDEYEN, Paul. (Eds.). Corpus Christianorum, Continuatio Medievalis LXIX, Brepols: Turnhout, 1996.

RÉGNIER-BOHLER, Danielle. "Vozes literárias, vozes místicas". In: KLAPISCH-ZUBER, Christiane. (Org.). História das Mulheres no Ocidente. Tradução Francisco Barba e Teresa Joaquim. São Paulo/Porto: Ebradil/ Afrontamento, 1990, p. 517-591 (Vol. 2: A Idade Média)

RUH, Kurt. Storia della Mistica Occidentale: mistica femminile e mistica fracescana delle origini. Traduzione de Giuliana Cavallo-Guzzo e Cesare de Marchi. Milano: Vita e Pensiero, 2002.

SCHWARTZ, Sílvia. "Marguerite Porete: Mística, Apofatismo e Tradição de Resistência". Numen: Revista de estudos e pesquisa da religião. Juiz de Fora, vol. 6, $\mathrm{n}^{\circ}$ 2, 2010, p.109-126. Disponível em: https://periodicos.ufjf.br/index.php/numen/article/view/21648. Acesso em: 20 abr. 2020.

SUZUKI, Daisetz Teitaro. “An Interpretation of Zen Experience”. In: Studies in Zen. London: Rider and Company, 1955, p. 61-84. 
TROCH, Lieve. "Mística feminina na Idade Média. Historiografia feminista e descolonização das paisagens medievais". Revista Graphos, v. 15, n. 1, 2013, p. 1-12. Disponível em: https://periodicos.ufpb.br/ojs2/index.php/ graphos/article/view/16324. Acesso em: 10 jun. 2015.

VANNINI, Marco. Mistica e filosofia. Firenze: Le Lettere, 2007.

VASCONCELOS, Ana Rachel Godim Cabral de e XXXXX. "Hildegard von Bingen e Elisabeth von Schönau: a correspondência (Cartas 201-201r) entre duas místicas visionárias do séc XII". Trilhas Filosóficas, Dossiê Filosofia e Mística, ano 13, n. 1, 2020, p. 35-54. Disponível em: http://natal.uern.br/periodicos/index.php/RTF/article/view/2396. Acesso em: 2 dez. 2020.

VELASCO, Juan Martin. El fenómeno místico: estudio comparado. Madrid: Trotta, 1999.

YUNES, Eliana. "A poética como mediação entre filosofia e mística". In: PINHEIRO, Marcus Reis e BINGEMER, Maria Clara Lucchetti (Orgs.). Mística e filosofia. Rio de Janeiro: PUC-Rio, 2010, p. 71-79. 